\title{
ALINHAMENTO DAS ESTRATÉGIAS DE UMA ENTIDADE PÚBLICA: UM ESTUDO DE CASO ${ }^{12}$
}

\section{ALIGNMENT OF THE STRATEGIES OF A PUBLIC AUTHORITY: A CASE'S STUDY}

\section{ALINEAMIENTO DE LAS ESTRATEGIAS DE UNA AUTORIDAD PÚBLICA: UN ESTUDIO DEL CASO}

Marcelo Medeiros da Rosa, Mestrando em Administração pela Universidade do Sul de Santa Catarina (UNISUL). Endereço Profissional: Caixa Econômica Federal, Servidão Na Sra. de Lurdes, 111, Agronômica - Florianópolis - SC - Brasil, CEP 88025-220. Telefone: (048) 3722-5000. E-mail: mmr2801@yahoo.com.br.

Sérgio Murilo Petri, Doutor em Engenharia de Produção pela Universidade Federal de Santa Catarina (UFSC). Endereço Profissional: Universidade Federal de Santa Catarina (Departamento de Contabilidade), Campus Reitor João David Ferreira Lima - Trindade Florianópolis - Santa Catarina - Brasil - CEP 88040-970 Telefone: (048) 3721-9000. URL da Homepage: http://dvl.ccn.ufsc.br/ccn/ E-mail: smpetri@gmail.com.

Fabiano Domingos Bernardo, Mestrando em Contabilidade pela Universidade Federal de Santa Catarina (UFSC). Endereço Profissional: Departamento Nacional de Infraestrutura de Transportes (DNIT/SC), Rua Álvaro Mullen da Silveira, 104, Centro - Florianópolis - SC Brasil, CEP 88020-180. Telefone: (048) 9953-7448. E-mail: fabiano_bernardo@ hotmail.com.

Carlos Visani Júnior, Bacharel em Administração Pública pela Universidade do Estado de Santa Catarina (UDESC/ESAG). Endereço Profissional: Caixa Econômica Federal, Servidão $\mathrm{N}^{\mathrm{a}}$ Sra. de Lurdes, 111, Agronômica - Florianópolis - SC - Brasil, CEP 88025-220. Telefone: (048) 3722-5000. E-mail: cacovjr@gmail.com.

Patrícia Bianco, Graduanda em Ciências Contábeis pela Universidade Federal de Santa Catarina (UFSC). Endereço Profissional: Instituto Federal de Educação, Ciência e Tecnologia de Santa Catarina (IFSC/SC), Av. Mauro Ramos n 950, bairro Centro CEP: 88020-300. Telefone: (048) 3371-8707. E-mail: patriciabianco@outlook.com.

\section{RESUMO}

Este artigo tem por objetivo propor o alinhamento estratégico de um ente da Administração Pública como proposta de melhorar a gestão estratégica, organizacional e orçamentária e os

\footnotetext{
${ }^{1}$ Artigo submetido em 16/03/2014, ${ }^{1}$ revisado em 10/07/2014, aceito em 10/10/2014 e divulgado em 01/12/2014 pelo Editor João Carlos Hipólito Bernardes do Nascimento, após double blind review.

${ }^{2}$ Artigo Apresentado na 33a SEMEAD, da Universidade Estadual de Maringá, PR. Setembro de 2013.

GєCont, v. 1, n. 2, Floriano-PI, Jul-Dez. 2014.
} 
serviços ofertados aos cidadãos. A ferramenta escolhida para este processo é o Balanced Scorecard (BSC), metodologia apresentada por Kaplan e Norton, em 1992, para implantação da estratégia organizacional, e muito difundida em empresas privadas que, com as devidas adaptações, pode ser utilizado por organizações públicas. Quanto aos aspectos metodológicos, o estudo apresenta caráter exploratório, com abordagem qualitativa e é classificado como um estudo de caso. Os instrumentos de pesquisa foram: a análise documental; a aplicação de questionário semiestruturado com a direção da Fundação Cultural de Florianópolis Franklin Cascaes (FCFFC); e a observação, mediante visitas à entidade e aos projetos por ela promovidos, ocorridas no ano de 2011. A partir da análise dos dados e da adoção do Mapa Estratégico como ferramenta de gestão, constataram-se as vantagens da utilização do Balanced Scorecard (BSC) na esfera pública, por meio da interação entre os 14 objetivos estratégicos das quatro perspectivas e a Missão da FCFFC.

Palavras-chave: Alinhamento Estratégico; Mapa Estratégico; Setor Público; Balanced Scorecard.

\begin{abstract}
This paper aims to propose the strategic alignment of an entity of the Public Administration as a proposal for improving the strategic, organizational and budget management and services offered to citizens. The chosen tool for this process is the Balanced Scorecard (BSC) methodology presented by Kaplan and Norton in 1992 to implement the organizational strategy and widespread in private companies, mutatis mutandis, can be used by public organizations. Regarding methodological aspects, the study presents exploratory, qualitative approach and is classified as a case's study. The research instruments used were: document analysis; the application of semi-structured questionnaire with the direction of the Cultural Foundation of Franklin Cascaes Florianópolis (FCFFC); and observation through visits to the entity and the projects promoted by it, occurred in 2011. From the analysis of the data and the adoption of the Strategy Map as a management tool, it appears that the advantages of using the Balanced Scorecard (BSC) in the public sphere, through the interaction between the 14 strategic objectives of the four perspectives and Mission FCFFC.
\end{abstract}

Keywords: Strategic Alignment; Strategic Map; Balanced Scorecard.

\title{
RESUMEN
}

Este trabajo tiene como objetivo proponer la alineación estratégica de una entidad de la Administración Pública como una propuesta para mejorar la, gestión y servicios de la organización y el presupuesto estratégico que ofrece a los ciudadanos. La herramienta elegida para este proceso es la metodología Balanced Scorecard (BSC) presentado por Kaplan y Norton en 1992 para poner en práctica la estrategia de la organización y generalizada en las empresas privadas, mutatis mutandis, puede ser utilizado por las organizaciones públicas. En cuanto a los aspectos metodológicos, el estudio presenta un enfoque exploratorio, cualitativo y se clasifica como un estudio del caso. Los instrumentos de investigación fueron: análisis de documentos; la aplicación de un cuestionario semiestructurado con la dirección de la Fundación Cultural de Franklin Cascaes Florianópolis (FCFFC); y la observación a través de visitas a la entidad y los proyectos promovidos por el mismo, se produjo en el año 2011 A partir del análisis de datos y la adopción del Mapa Estratégico como herramienta de gestión, parece que las ventajas del uso del Balanced Scorecard (BSC) en la esfera pública, a través de la interacción entre los 14 objetivos estratégicos de las cuatro perspectivas y la Misión de FCFFC. 
Palabras clave: Alineamiento Estratégico; Mapa Estratégico; Cuadro de Mando Integral.

\section{INTRODUÇÃO}

7 mbora esteja no topo do ranking dos países com maior carga tributária - se comparado com outros países que compõe o BRIC - Brasil, Rússia, Índia e China (AMARAL, 2010), o Estado brasileiro oferece à população uma contrapartida inferior ao esperado, tendo-se a impressão que nada ou muito pouco do que deveria ser feito é efetivamente realizado.

As assertivas de Olenike et al. (2012, p. 02) endossam tal percepção, apresentando a dicotomia sobre a arrecadação tributária e os serviços públicos no país:

\footnotetext{
Entre os 30 países com a maior carga tributária, o Brasil CONTINUA SENDO o que proporciona o pior retorno dos valores arrecadados em prol do bem estar da sociedade; a Austrália, seguida dos Estados Unidos, da Coréia do Sul e do Japão, é o país que melhor faz aplicação dos tributos arrecadados, em termos de melhoria da qualidade de vida de seus cidadãos; o Brasil, com arrecadação altíssima e péssimo retorno desses valores, fica atrás, inclusive, de países da América do Sul, como Uruguai e Argentina.
}

Ao transparecer que sua gestão fiscal e orçamentária é ruim o Estado atesta que o trato com os recursos públicos busca unicamente cumprir dispositivos legais, preterindo-se o planejamento e a gestão correta de seus recursos para o desenvolvimento de ações e políticas de governo que atendam aos anseios da população (O GLOBO, 2005).

Ante o exposto, é necessário promover uma reflexão sobre a forma como a Administração Pública estabelece as metas e estratégias dos programas desenvolvidos. Esta reflexão objetiva aferir eficiência, eficácia e efetividade das ações e o alinhamento entre elas e a missão da entidade que as executam.

Entende-se que o planejamento estratégico e o estabelecimento de prioridades no setor público necessitam de estudos mais aprofundados uma vez que são escassos quando comparados ao setor privado. Questões como concorrência e vantagens competitivas, presentes na realidade das empresas que visam lucro, deixam de ser o foco, passando a ser a efetividade dos serviços prestados à sociedade.

Assim, nasce o problema de pesquisa que auxiliará na reflexão sobre o tema e quais passos os pesquisadores que se interessarem pelo assunto deverão seguir: Como promover o alinhamento estratégico dos entes da Administração Pública e melhorar a gestão estratégica, orçamentária, organizacional e melhorar os serviços oferecidos?

A partir dos estudos de Gomes e Liddle (2009) e Andrews et al. (2011), o objetivo da pesquisa é testar se o Mapa Estratégico do Balanced Scorecard pode ser utilizado como ferramenta de alinhamento estratégico para os entes da Administração Pública. Do ponto de vista estrutural, este artigo apresentará um embasamento teórico sobre o BSC, estratégia e planejamento estratégico e suas características no setor público. São apresentados, na sequência, a metodologia utilizada e o estudo de caso, desenvolvido em uma fundação municipal que possuía, até o primeiro semestre de 2013, status de secretaria municipal de Florianópolis e, por fim, são apresentadas as considerações finais e o referencial bibliográfico utilizado. 


\section{FUNDAMENTAÇÃO TEÓRICA}

\subsection{Balanced Scorecard (BSC): Quadro Conceitual}

O desenvolvimento do Balanced Scorecard, ocorrido no início da década de 1990, teve como pano de fundo a perda de competitividade das indústrias americanas. Com a perda da liderança tecnológica e de gestão para indústrias japonesas e a necessidade de modernização dos métodos de avaliação de desempenho, iniciou-se o debate sobre um método que permitisse a mensuração de resultados de maneira mais ampla (COSTA, 2006).

Enquanto a avaliação de desempenho adotada pelos americanos se baseava nos métodos tradicionais existentes - indicadores exclusivamente financeiros/contábeis, as empresas japonesas avaliavam sua performance por meio de outros componentes relevantes, como produtividade, qualidade dos produtos e excelência nos processos.

A mudança no escopo quanto à avaliação do desempenho se deu pelo fato de que a ênfase excessiva em resultados financeiros concentra as atividades em soluções exclusivamente de curto prazo. Ao preterir os cenários de longo prazo, as organizações comprometem seu desenvolvimento futuro e o sucesso organizacional. Assim, para se obter um diferencial no acirrado mercado global, é necessário avaliar o desempenho organizacional sobre várias perspectivas - ativos intangíveis e não mais apenas sob o prisma financeiro ativos tangíveis e métodos contábeis tradicionais (BASAGLIA et al., 2010).

Diante desse paradigma, Kaplan e Norton desenvolveram o Balanced Scorecard, que permite avaliar o desempenho em dimensões financeiras e não financeiras como "um complemento à medida financeira, suprindo sua deficiência em monitorar os ativos intangíveis essenciais para o crescimento futuro." (BASAGLIA et al., 2010, p. 06).

No primeiro momento, a metodologia tinha como foco exclusivo a mensuração do desempenho organizacional, entretanto, após os primeiros testes práticos em empresas voluntárias, verificou-se que o BSC é um sistema de gestão que contribui para a implementação das estratégias e na mobilização de toda a organização para o cumprimento dos objetivos estratégicos.

O BSC contribui com a implantação da estratégia ao posicioná-la como o cerne organizacional, tirando os aspectos financeiros do topo da hierarquia e colocando-os no mesmo patamar de outras questões pertinentes ao negócio - como a gestão dos processos e o relacionamento da empresa com seus clientes. Esta situação se evidencia pelo método complementar as análises financeiras com análises sobre a satisfação do consumidor, market share, processos internos e as atividade de melhoria e inovação das organizações - análises operacionais que norteiam o desempenho financeiro futuro.

Outros benefícios verificados a partir da implementação da ferramenta são a melhoria no feedback e o aprendizado estratégico, uma vez que definidas as medidas referenciais e as revisões gerenciais de curto prazo, consegue-se analisar como os resultados foram ou não alcançados e se as expectativas para o futuro continuam viáveis. Assim, visualiza-se a execução e a manutenção de metas possíveis de serem atingidas e se possibilita a geração de novas ideias (KAPLAN; NORTON, 1997).

Os autores da metodologia apontam dois aspectos para reforçar a percepção que o BSC transcende a relação entre questões financeiras e não-financeiras, a saber: enaltece a necessidade dos colaboradores, dos níveis hierárquicos baixos e médios, saberem com clareza quais são os indicadores financeiros e não-financeiros para boa execução de suas rotinas diárias e para que os altos executivos possam compreender o resultado de suas decisões de 
longo prazo; e para que se consiga identificar e alinhar os fatores críticos do sucesso organizacional que apontam para o caminho mais curto para o cumprimento da estratégia de longo prazo (KAPLAN; NORTON, 1997).

Utilizando esta metodologia, a empresa transforma a missão e a estratégia em objetivos, alinhando-os de tal forma que facilitem o entendimento entre os diversos níveis da organização e canalizando os esforços para a realização dos objetivos propostos por meio da melhoria nos processos organizacionais (FAGUNDES et al., 2007).

Na construção do BSC, a estrutura proposta pelos autores para traduzir a estratégia em termos operacionais é, tradicionalmente, dividida em quatro perspectivas: financeira, clientes, processos internos, crescimento e aprendizagem. No entanto, esta estrutura não precisa ser necessariamente desenvolvida de maneira idêntica, sendo possível a adoção de mais ou menos perspectivas com conteúdos mais adequados para organização que está implantando a ferramenta (KAPLAN e NORTON, 1997).

Embora experiências práticas tenham demonstrado a eficácia do BSC no que concerne ao alinhamento estratégico de todas as áreas e processos da organização, alguns autores apontam a existência de pontos críticos que dificultam a implantação integral ou mesmo parcial da ferramenta.

Entre eles, os próprios pesquisadores que propuseram o BSC apontam os possíveis obstáculos, a citar: a falta de comprometimento da alta administração; o envolvimento de poucas pessoas; encastelamento do scorecard no topo da estrutura; processos de desenvolvimento muito longos; tratar o BSC como projeto de área de sistemas; contratação de consultoria inexperiente; e implantação do BSC apenas para fins de remuneração (KAPLAN; NORTON, 2000).

Ao se analisar os obstáculos supracitados sob a ótica da Administração Pública, observa-se que devem ser incluídos como barreiras para implementação do BSC a falta de interesse na continuidade das ações e estratégias de gestões passadas e a falta de preparo do staff e/ou dos gestores públicos, muitas vezes meros ocupantes de cargos comissionados à disposição de serviços eleitoreiros e sem compromisso com a sociedade (SILVA NETO, 2006).

\subsubsection{O planejamento estratégico e o Balanced Scorecard na esfera pública}

O planejamento estratégico estatal não difere do ponto de vista conceitual do planejamento estratégico de organizações do setor privado (MARQUES et al., 2009). A utilização do planejamento estratégico por entidades estatais, de acordo com os autores, ocorre por duas razões: A primeira, devido à crescente limitação de recursos financeiros, a qual impõe restrições para o custeio e financiamento dos grandes investimentos necessários ao desenvolvimento, requerendo uma ação planejada; E a segunda, graças à eminente postura proativa da sociedade - aumento da pressão por maior qualidade e equidade na prestação de serviços.

O processo de planejamento possui papel secundário na Gestão Pública, conforme ditames da democracia representativa. Na maioria das vezes, este processo visa apenas atender aspectos formais - contábeis e financeiros, não sendo utilizado como importante instrumento de transformação social (SILVA NETO et al., 2006).

Perde-se a percepção de como que é importante agir estrategicamente para atingir os objetivos traçados. Planejar estrategicamente "é criar condições para que as organizações decidam rapidamente diante de oportunidades e ameaças, otimizando as vantagens competitivas em relação ao ambiente concorrencial em que atuam" (COBRA, 1991, p.16). 
O processo de planejamento estratégico deve ser utilizado, na concepção de Kaplan e Norton (2000, p. 306), [...] para ajudar as organizações a alcançar os objetivos estratégicos [...]". Os mesmos autores sugerem que o processo siga a seguinte sequência:

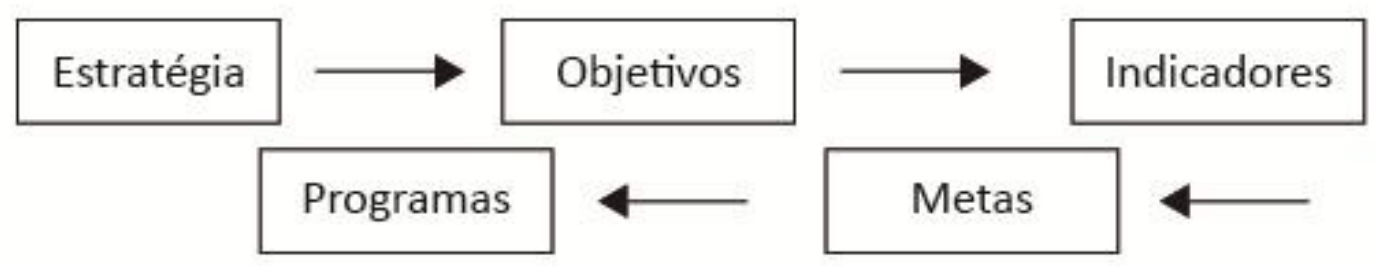

Figura 01: Processo de Planejamento Estratégico

Fonte: Kaplan; Norton, 2000, p. 306.

$\mathrm{Na}$ interação entre estratégia e o Balanced Scorecard, surge o conceito de que estratégia corresponde a "[...] um conjunto de hipóteses sobre os relacionamentos de causa e efeito; entre os objetivos e as medidas do desempenho obtido no esforço para alcançá-los" (COSTA, 2006, p. 12).

A relação causa e efeito corresponde pela sequência lógica de afirmações cuja dependência tem caráter existencial. No caso de inexistência da primeira afirmação, a segunda perde coerência. Trata-se da relação "se-então". Para exemplificar: "Se aumentarmos o investimento em divulgação, então haverá mais público nos espetáculos'.

Kaplan e Norton (2000) e Niven (2007) consideram o BSC um modelo dinâmico e flexível que pode ser aplicado a qualquer organização. $\mathrm{Na}$ visão dos autores, qualquer organização, seja pública ou privada, necessita de comunicar a sua estratégia e os seus objetivos, bem como as medidas de desempenho em todos os níveis da organização. Sendo assim, o BSC é um modelo aplicável também ao setor público, desde que adaptado à realidade da organização.

A adaptação do BSC em organizações públicas parte do princípio central que move uma empresa privada. Enquanto estas buscam o lucro (foco na perspectiva financeira), uma entidade governamental busca o atendimento ao cidadão (foco na perspectiva clientes). Logo, as estratégias para a concretização dos respectivos objetivos são invariavelmente diferentes e, por seus resultados terem um cunho, na maioria das vezes, subjetivos, a Administração Pública encontra dificuldades para a definição estratégica de suas ações. (DUTRA; LUZ, 2008).

De acordo com Kaplan e Norton, (2000), o primeiro registro da adoção do Balanced Scorecard na esfera pública se deu em na cidade de Charlotte, nos Estados Unidos. No início da década de 1990 a cidade comunicava, por meio de sua missão e visão, o foco de atuação: a prestação de serviços de alta qualidade à população. Entretanto, não havia consenso entre os gestores sobre a maneira de executá-los, tampouco saber exatamente quais serviços deveriam ser priorizados utilizando-se os limitados recursos (KAPLAN; NORTON, 2000).

A Administração e os munícipes, organizados sob a forma de um grupo denominado Conselho Municipal, estabeleceram cinco temas centrais que norteariam a destinação dos recursos e os programas de governo por dez anos. Após discussões, a equipe identificou os objetivos estratégicos essenciais e definiu a perspectiva dos "clientes" como a mais importante - todas as ações de governo deveriam atender aos interesses e necessidades dos cidadãos de Charlotte. 
Cabe ressaltar que as primeiras ações de melhoria na gestão de entidades governamentais são anteriores ao BSC e tinham como foco a avaliação de desempenho. No final da década de 1880, iniciou-se em universidades europeias o debate sobre a necessidade do Estado ser mais eficiente e racional como as empresas do setor privado, tendo-se, a partir deste período, um enfoque científico e mais orientado aos negócios (DUTRA; ENSSLIN, 2005; PETERS; PIERRE, 2010).

De acordo com Bresser-Pereira (2000) e Campos et al. (2000), a partir da década de 1990 agregaram a responsabilização pelos atos praticados no exercício da função pública, fato que no Brasil desencadeou na formulação da Lei de Responsabilidade Fiscal - Lei Complementar $n^{\circ}$. 101 de 04 de maio de 2000, e na mudança de enfoque da gestão - do modelo burocrático para o modelo gerencial.

Ainda de acordo com Bresser-Pereira (2000), essa mudança ocorreu pelo fato da burocracia brasileira dificultar a relação entre o Estado brasileiro e a população. Lentidão nos processos, falta de excelência nos serviços e sensação de impunidade aos gestores públicos que cometeram algum tipo de infração foram sinais de ineficiência do Poder Público apontados pelo empresariado em pesquisa realizada pela PricewaterhouseCoopers Consultoria em 2006 (MELO et al., 2009).

Logo, o esgotamento do modelo burocrático proporcionou a reflexão sobre a existência de métodos de gestão com características mais próximas da esfera privada e alinhado ao objetivo finalístico das organizações públicas, como o Balanced Scorecard.

\subsubsection{O Alinhamento Estratégico por meio do Mapa Estratégico do BSC}

Para a operacionalização do BSC é necessária uma compreensão holística da organização - do contexto e do ambiente em que está inserida, com quem se relaciona e quais desafios está buscando. Depois, deve-se observar o planejamento estratégico da organização, a fim de informar os rumos que deverão ser seguidos (ENSSLIN et al., 2008).

Saber aonde se quer chegar e quais são as prioridades são pontos, fundamentais no processo de elaboração do BSC, que deve representar o pensamento e as energias da equipe que o elabora. Caso contrário, sem o engajamento de todos os envolvidos, o resultado mais provável é o fracasso (KAPLAN; NORTON, 1997).

Alinhamento estratégico corresponde à adequação e integração funcional entre o ambiente externo e interno - integração entre mercados, estrutura administrativa e recursos financeiros, tecnológicos e humanos, com o objetivo de desenvolver as competências necessárias para maximizar o desempenho organizacional (KAPLAN; NORTON, 2006).

Este alinhamento integra as ações organizacionais ao comunicar a estratégia a todas as unidades/setores de modo que todos colaborem para a realização das metas e objetivos traçados, agregando valor à organização.

Com as estratégias alinhadas, todas as áreas podem oferecer mais do que suas atribuições tradicionais - sinergia e auxiliar no alcance de seus objetivos, como por Antunes e Gonçalves (2010, p. 03):

- Recursos Humanos - desenvolvimento de programas de competências estratégicas, programas de desenvolvimento e liderança, programas de comunicação estratégica e, programas de gestão de desempenho;

- Tecnologia da Informação - automatização das principais áreas operativas da empresa, explorar a tecnologia da informação para 
melhorar a rentabilidade do negócio, promover a análise, interpretação e o compartilhamento de informações e conhecimento, fornecer soluções tecnológicas inovadoras e criativas que ajudem as áreas de negócios;

- Orçamento e Finanças - reduzir o tempo gasto com funções rotineiras e aumentar o tempo dedicado a funções analíticas para melhorar o processo decisório, apoiar clientes internos e unidades de negócios preservando a rentabilidade da organização por meio de informações úteis, divulgar informações claras e confiáveis, identificar e avaliar oportunidades de melhor aproveitamento dos recursos.

A forma mais indicada para visualizar o alinhamento estratégico ocorre por meio da construção de um mapa da estratégia - ou Mapa Estratégico. Por Mapa Estratégico entendese a representação visual das relações de causa e efeito entre os componentes estratégicos de uma organização. Trata-se de um instrumento de visualização que permite a descrição consistente da tática pré-estabelecida, auxiliando na definição e gestão dos objetivos e indicadores estratégicos (KAPLAN; NORTON, 1997).

Ao descrever a lógica da estratégia para toda a organização, percebe-se, de modo claro e objetivo, quais os processos internos críticos que criam valor para clientes e acionistas, bem como de quais são os ativos intangíveis imprescindíveis para respaldá-los (COSTA, 2006).

De acordo com Niven (2007), o Mapa Estratégico comunica a estratégia para todos da organização, alinhando os esforços e refinando as ações desenvolvidas. Além disso, com os mapas da estratégia, consegue-se gerir por informações concretas e não por instinto, pois a ferramenta facilita a identificação e monitoramento dos objetivos estratégicos e das ações que agregam valor à missão corporativa. Representa, portanto, a imprescindível ligação entre a elaboração e a concretização da estratégia.

\section{METODOLOGIA}

No que diz respeito à metodologia, o presente estudo, possui origem exploratória e descritiva, pois visa desenvolver entendimento e descrever características de determinado fenômeno e é ainda classificada como estudo de caso que, segundo Gil (1999, p.72): “é caracterizado pelo estudo profundo e exaustivo de um ou de poucos objetos, de maneira a permitir o seu conhecimento amplo e detalhado [...]".

Quanto aos procedimentos teóricos, trata-se de uma pesquisa documental e bibliográfica, por ter como fonte de pesquisa dados fornecidos pela coordenação da entidade e extraídos da homepage da Fundação, fundamentados por livros e artigos científicos sobre o tema. A abordagem do problema escolhida foi, de acordo com Raupp e Beuren (2006), qualitativa, pois se buscou uma análise aprofundada do fenômeno em estudo.

Além da análise documental, os procedimentos metodológicos aplicados para a consecução do objetivo de propor um modelo de Mapa Estratégico para alinhamento da estratégia da organização, foram a aplicação de um questionário aberto, semi-estrututurado, aplicado com a Coordenação Artística e a Superintendência da Fundação Cultural de Florianópolis Franklin Cascaes, e visitas à sede e aos projetos desenvolvidos nos anos de 2011 e 2012. 


\section{ANÁLISE DOS DADOS}

\subsection{Caracterização do Caso}

Criada pela Lei Municipal $\mathrm{n}^{\circ}$. 2647, de 29 de julho de 1987, a Fundação Franklin Cascaes atua como agente facilitador e fomentador da produção cultural da cidade de Florianópolis. A instituição tem suas ações focadas na promoção da cultura como fator de desenvolvimento e inclusão social, fazendo da arte uma rica fonte de educação, aprendizagem, entretenimento e oportunidades.

A Fundação, que leva o nome do artista, historiador e pesquisador Franklin Joaquim Cascaes (in memoriam), investe em programas e iniciativas que visam promover, fortalecer e difundir manifestações culturais tradicionais e contemporâneas, visando à democratização do acesso aos bens culturais; o respeito à pluralidade das expressões artísticas; a valorização e preservação do patrimônio cultural; e a promoção de um diálogo permanente com a cidade para a construção de políticas públicas para a cultura. Entre as ações da FCFFC destacam-se os eventos: Festival de Teatro Isnard Azevedo; Encontro das Nações; Maratona Fotográfica de Florianópolis e o Encontro de Bois de Norte a Sul; e os projetos Orquestra Escola, Centro de Referência da Renda de Bilro e Oficinas de Arte-educação nas Comunidades (FCFFC, 2011).

Além de coordenar diversos eventos, administrar os espaços culturais e zelar pelo patrimônio material e imaterial do município, a FCFFC possui uma editora para divulgação da produção catarinense e gerencia o Fundo Municipal de Cultura e a Lei municipal de Incentivo à Cultura para o financiamento de projetos culturais. Anualmente, cerca de 250 mil pessoas são beneficiadas direta ou indiretamente pelas atividades culturais apoiadas ou realizadas pela Fundação.

Dadas suas características, a entidade tem como Missão: Estimular e promover a produção artística e cultural, valorizando e preservando o patrimônio material e imaterial de Florianópolis, com respeito à diversidade e à democratização do acesso à cultura.

A Visão especifica aonde a organização pretende estar em determinado momento futuro, sendo representada pela seguinte assertiva: "ser reconhecida por sua excelência na valorização e promoção da arte teatral, democratizando o acesso à cultura e melhorando a qualidade de vida da sociedade".

Os Valores, que correspondem às convicções mais profundas de uma entidade, são representados pelas seguintes afirmações: (i) Respeito ao indivíduo e às diferenças; (ii) Incentivo à liberdade de expressão; (iii) Uso responsável dos recursos e do patrimônio público; (iv) Estímulo à produção e difusão cultural.

A estratégia da entidade para consecução de seus objetivos, cumprir sua Missão e Visão, tendo seus Valores como orientação se dá por meio das seguintes ações: (i) Foco na qualidade dos espetáculos e dos profissionais que atuam nas peças e inserções artísticas; (ii) Ampla divulgação dos eventos e ações promovidas na mídia; (iii) Criação de espaços alternativos para realização dos espetáculos, oficinas e seminários; (iv) Fortalecimento das parcerias com os patrocinadores para garantia da realização das atividades da Fundação (FCFFC, 2011).

Após a apresentação da entidade e dos elementos estratégicos que subsidiam a elaboração do Mapa da Estratégia, passa-se à exposição da pesquisa e à discussão dos resultados. 
Figura 02: Mapa Estratégico da Fundação Cultural de Florianópolis Franklin Cascaes.

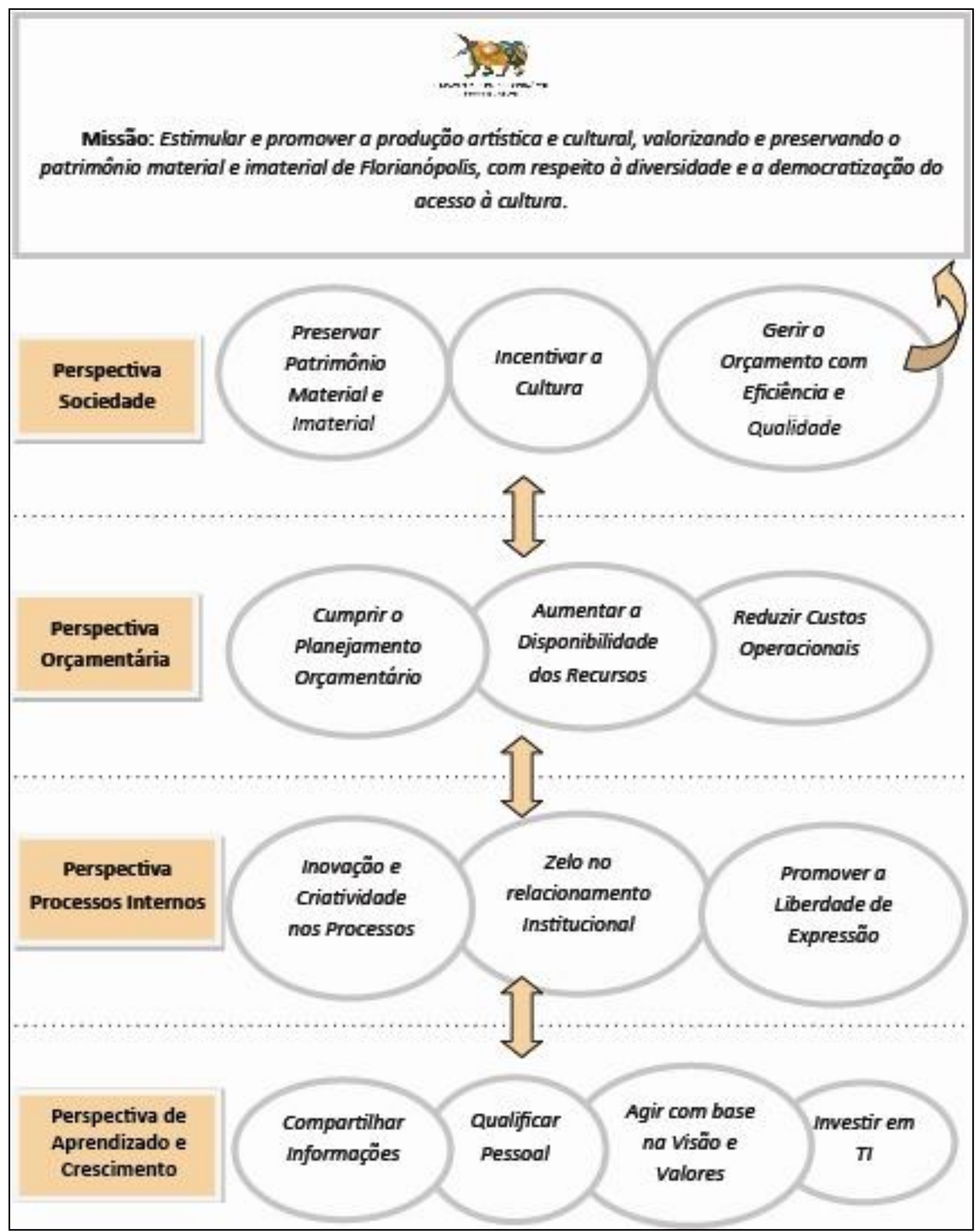

Fonte: Os Autores, 2013.

\subsection{O desenvolvimento do Mapa Estratégico}

No desenvolvimento do Mapa Estratégico como ferramenta de alinhamento estratégico para a Fundação Franklin Cascaes não se utilizou um modelo padrão. Como 
preconizado pelos autores do BSC, houve a formulação de um gabarito adaptado às características e objetivos da entidade (KAPLAN; NORTON, 2006).

A primeira adaptação ocorreu com a substituição da perspectiva clientes por perspectiva da sociedade, por traduzir de forma mais equânime o verdadeiro cliente da Administração Pública e, por este motivo, definiu-a como o topo da hierarquia. Os objetivos estratégicos desta perspectiva são, a saber: (i) Preservar o Patrimônio Material e Imaterial de Florianópolis; (ii) Incentivar a Cultura; e (iii) Gerir o Orçamento com eficiência e Qualidade. Sobre os objetivos estabelecidos para a perspectiva orçamentária, estabelecidos a partir do princípio de que a entidade deve gerir de maneira responsável seus recursos, tem-se: (i) Cumprir o Planejamento Orçamentário; (ii) Aumentar a Disponibilidade dos Recursos; e (iii) Reduzir os Cursos Operacionais.

Os objetivos estratégicos da perspectiva processos internos são, a saber: (i) Promover a Liberdade de Expressão; (ii) Inovação e Criatividade nos Processos; e (iii) Zelo no relacionamento Institucional.

Quanto aos objetivos estratégicos da perspectiva aprendizado e crescimento, tem-se: (i) Qualificar Pessoal; (ii) Investir em Tecnologia da Informação; (iii) Compartilhar Informações Estratégicas e; (iv) Agir com base na Visão e os Valores da Entidade.

A partir dos objetivos estratégicos supracitados, desenvolveu-se o Mapa Estratégico da organização. Este processo teve como objetivo principal criar valor sustentável por meio dos ativos intangíveis da FCFFC - pessoas, gestão da informação, processos internos, gestão transparente dos recursos financeiros e relacionamento com os clientes, e promover a melhoria na gestão estratégica, orçamentária e organizacional.

\subsection{Desdobramento da Estratégia - Interações Causa-Efeito}

Com base na literatura apresentada até o momento e nas sugestões de Farias et al. (2012), a analise do Mapa Estratégico elaborado foi feita de baixo para cima, pela perspectiva aprendizado e crescimento, seguindo até a perspectiva da sociedade por meio de relações de causa-efeito entre os objetivos estratégicos.

Com a equipe de trabalho qualificada, investimentos em Tecnologia da Informação, métodos que estimulem e facilitem o compartilhamento de informações e agindo de acordo com a Visão e dos Valores da entidade, a Fundação estará: promovendo a inovação e criatividade como norteadoras de seus processos internos, atuando com zelo pelo relacionamento institucional com parceiros, fornecedores e sociedade, além de fazer a gestão do orçamento com qualidade eficiência e qualidade. Esta interação causa-efeito se dá pelo fato de que, uma vez qualificados, os colaboradores tendem a tornar o ambiente de trabalho mais criativo, democrático e favorável a inovações; com o suporte da tecnologia de informação adequada, consegue-se compartilhar as informações; ao compartilhar as informações e conhecimentos, contribui-se para a promoção da liberdade de expressão. Por fim, ao agir com base na visão e os valores da entidade, os colaboradores atuarão de forma a cumprir todas as atividades previstas no planejamento orçamentário da organização em consonância com os objetivos delineados.

Reduzindo-se os custos operacionais é possível aumentar o número e a abrangência dos projetos e, por meio da relação causa-efeito, tem-se o aumento dos recursos necessários para a perenidade das iniciativas da entidade.

Por fim, com a promoção da liberdade de expressão artística e cultural, o incentivo à cultura e à preservação do patrimônio material e imaterial do município, atinge-se a Missão e 
a Visão da Fundação Franklin Cascaes e compreende-se a razão de ser de uma entidade pública - atender aos anseios da população.

Com a implementação do Mapa Estratégico, os elementos estratégicos pré-definidos em cada uma das perspectivas poderão ser monitorados, propiciando o feedback e o aprendizado organizacional. Esta situação se deve ao fato do processo de desenvolvimento deste modelo teórico ter ocorrido de forma integrada com os gestores da organização, tornando o modelo alinhado com objetivos de curto, médio e, principalmente, de longo prazo da Fundação.

Para sintetizar o Alinhamento Estratégico da Fundação Cultural de Florianópolis Franklin Cascaes, elaborou-se a Figura 03, seguindo modelo de Kaplan e Norton (2000):

Figura 03: Alinhamento das Atividades à Estratégia da FCFFC.

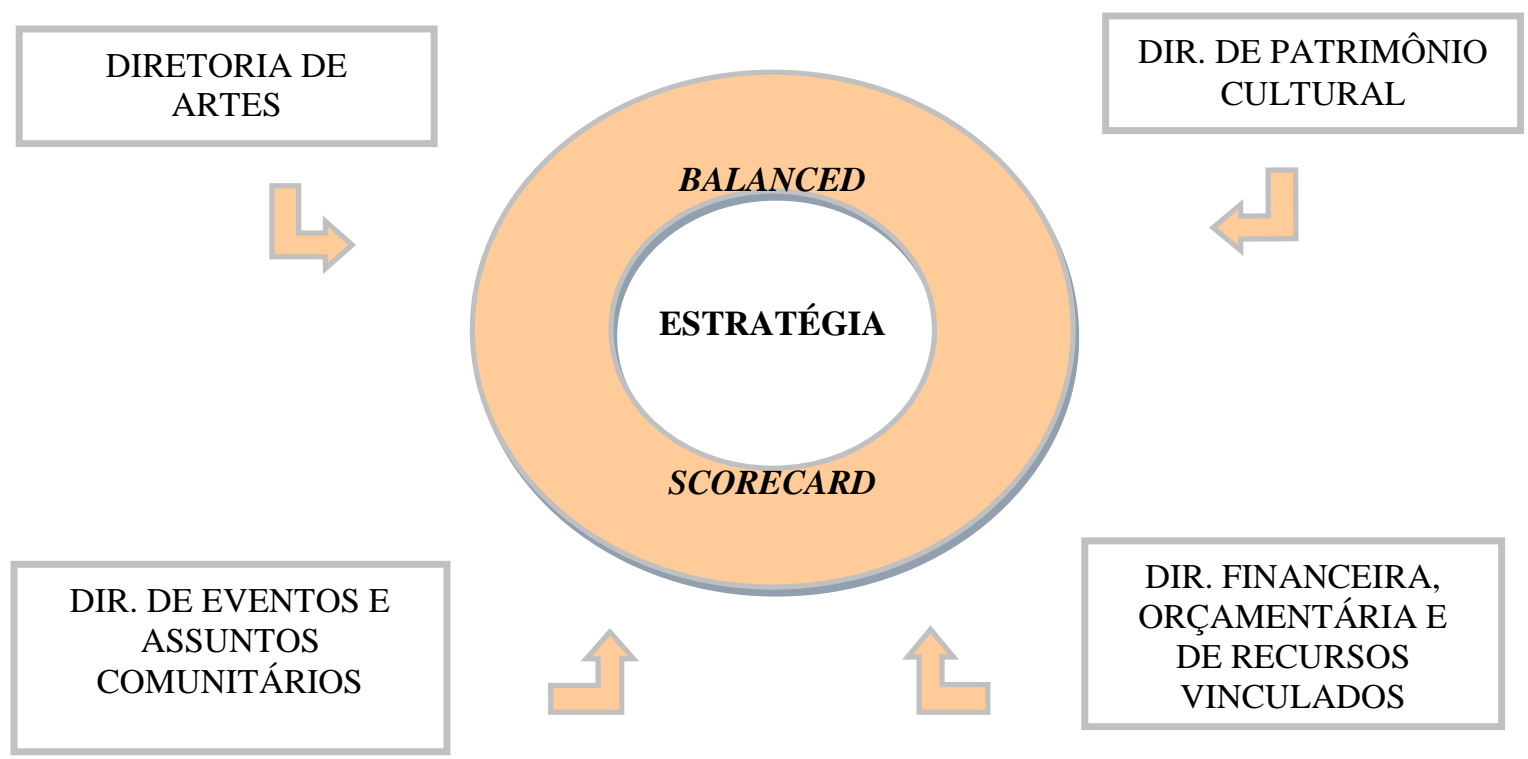

Fonte: Adaptado de Kaplan e Norton (2000).

\section{CONCLUSÕES}

Por meio desta pesquisa, percebe-se que a utilização do Balanced Scorecard como instrumento de gestão pode facilitar o desempenho das funções do administrador público. No entanto, como os próprios autores deste método indicam, não existe fórmula única para sua implantação. Cabe à equipe gestora a adequação da ferramenta à realidade organizacional, por meio da elaboração de objetivos estratégicos próprios e em consonância com a missão da entidade.

Viu-se que o BSC equilibra, por meio de suas perspectivas, os objetivos de curto e de longo prazo e os resultados almejados. Sua utilidade reside, também, na tradução da estratégia em objetivos estratégicos mensuráveis e na ligação lógica existente entre eles - causa e efeito, permitindo o entendimento, o controle e a execução das metas previamente propostas.

O trabalho identificou que os gestores da Fundação Cultural de Florianópolis Franklin Cascaes já possuem a missão, visão e estratégia - que são a base de sustentação para a construção do BSC. Coube, apenas, a adaptação das perspectivas à realidade organizacional, com a alteração da nomenclatura da perspectiva clientes para perspectiva sociedade. 
O objetivo desta pesquisa foi atendido pela validação do gabarito de Mapa Estratégico proposto como ferramenta de alinhamento estratégico da entidade estudada. Este modelo apresentou os objetivos estratégicos das áreas do FCFFC, a interação lógica existente entre eles, a melhoria dos serviços ofertados à população de Florianópolis e a possibilidade de cumprimento da missão da entidade.

Cabe salientar que é aceitável que o alinhamento estratégico não seja atingido rapidamente, tendo em vista as reavaliações e readequações constantes propostas pelo BSC. Sua consecução não depende apenas de circunstâncias operacionais, mas principalmente da intenção dos líderes e dos colaboradores de todas as diretorias da entidade. Para que ocorra a melhoria nos processos e na gestão dos aspectos financeiros, organizacionais e estratégicos, a metodologia deve estar inserida em seus sistemas de gerenciamento, permitindo a correta análise do desempenho e segurança na tomada de decisões.

Quanto às limitações, a presente pesquisa, por se tratar de uma pesquisa qualitativa, limitou-se a apresentar as interpretações dos pesquisadores sobre a realidade encontrada na organização estudada, não podendo ser copiado ou replicado em sua totalidade em outros entes públicos sem as devidas correções e adaptações - requisitos descritos por Kaplan e Norton como indispensáveis ao se utilizar o Balanced Scorecard como ferramenta organizacional.

Por fim, como sugestão a futuros investigadores, a realização de pesquisa caracterizada como ex-post-facto ao final de 2014 possibilitará a verificação sobre a aplicabilidade do alinhamento estratégico proposto, permitindo a identificação e correção de possíveis desvios e contribuindo para o aprimoramento do modelo.

\section{REFERÊNCIAS}

AMARAL, L. M. F. Brasil sobe no Ranking Mundial dos Países com Maior Carga Tributária. Estudos do IBPT. Disponível em:< http://ibpt.com.br/img/_publicacao/13891 /189.pdf>. Acesso em: 16 jan. 2012.

ANDREWS, R.; BOYNE, G. A.; MEIER, K. J.; O'TOOLE JR, L. J.; WALKER, R. M. Vertical Strategic Alignment and Public Service Performance. Public Administration. v.90, Inssue 1, p. 77-98, 2011. DOI: 10.1111/j.1467-9299.2011.01938.x.

ANTUNES; M. C.; GONÇALVES, A. O. Nível de Maturidade do Alinhamento Estratégico entre os Programas e/ou Ações do Plano Plurianual do Governo Federal Brasileiro e os Órgãos Responsáveis por sua Gestão. In: Encontro Nacional de Administração Pública e Governança - EnAPG 2010, Vitória. Anais. Vitória: EnAPG, 2010.

BASAGLIA, M. M.; OLIVEIRA, L. T. S.; NASCIMENTO; M. R.; PERIOTTO, A. J. Alinhamento da metodologia Balanced Scorecard ao planejamento estratégico de uma empresa de consultoria. In: Congresso Internacional de Administração, 2010, Ponta Grossa. Anais. Ponta Grossa, 2010.

BRESSER-PEREIRA, L. C. A Reforma Gerencial do Estado de 1995. RAP. Revista Brasileira de Administração Pública, Rio de Janeiro, v. 34, n.4, p. 7-26, 2000.

CAMPOS, A. M. S. M.; SANTIAGO JÚNIOR, D.; ÁVILA, J. Avaliação de gências reguladoras: uma agenda de desafios para a sociedade brasileira.. RAP. Revista Brasileira de Administração Pública, Rio de Janeiro, v. 5, p. 29-46, 2000

COBRA, M. Administração de Marketing. São Paulo: Atlas, 1991.

GєCont, v. 1, n. 2, Floriano-PI, Jan-Jun. 2014. 
COSTA, A. P. P. Balanced Scorecard: Conceitos e guia de implementação. São Paulo: Atlas, 2006.

DUTRA, A.; ENSSLIN, S. R. Avaliação do Desempenho de Órgãos Públicos: Proposta de um Estudo de Caso. In: X Congreso Internacional del CLAD sobre la Reforma del Estado y de la Administración Pública, 2005, Santiago. Anais do X Congresso, 2005.

DUTRA, A.; LUZ, M. R. H. Sistema de Avaliação de Desempenho das Secretarias de Desenvolvimento Regional do Governo do Estado de Santa Catarina: Resultados Preliminares da Aplicação de um Modelo Construtivista. In: III EnAPG - Encontro de Administração Pública e Governança - EnAPG 2008, Salvador. Anais. Salvador: EnAPG.

EDITORIAL. Fórmula da Injustiça. JORNAL O Globo, Caderno Economia, p. 22, 12 de julho de 2005.

ENSSLIN, L; ENSSLIN, S. R.; BORGERT, A.; LYRIO, A. D. M. V. L; Gerenciamento do Desempenho da Secretaria de Desenvolvimento Regional da Grande Florianópolis: Uma Proposta Advinda da Combinação do Balanced Scorecard e da Metodologia Multicritério de Apoio à Decisão Construtivista. In: III Encontro Nacional de Administração Pública e Governança - EnAPG 2008, Salvador. Anais. Salvador: EnAPG, 2008.

FAGUNDES, J.A; SOLER, C.C; FELIU, V. M. R.; LAVARDA, C. E. F. Tableau de Bord vs Balanced Scorecard. Revista de Contabilidade do Mestrado em Ciências Contábeis da UERJ, Rio de Janeiro, v. 12, n. 1, p. 1, janeiro/abril 2007.

FARIAS, S.; NUNES, G. S. F.; LYRIO, M. V. L.; PETRI, S. M.; LUNKES, R. J. O Desenvolvimento de Um Mapa Estratégico Como Ferramenta Para Comunicação da Estratégia em Uma Instituição Pública Federal de Ensino de Santa Catarina. In: $12^{\circ}$ Congresso USP de Controladoria e Contabilidade, 2012, São Paulo. $12^{\circ}$ Congresso USP de Controladoria e Contabilidade. São Paulo: FEA-USP, 2012. v. CDROOM. p. 1-16.

FCFFC, Fundação Cultural de Florianópolis Franklin Cascaes. Fomentar a Cultura é a Nossa Arte. Disponível em: <http://www.pmf.sc.gov.br/entidades/franklincascaes/>. Acesso em: 20 set. 2011.

GIACOMONI, J. Orçamento Público. 14 Ed. São Paulo: Atlas, 2007

GIL, A. C.; Como elaborar Projetos de Pesquisa. 4. Ed. São Paulo: Atlas, 1999.

GOMES, R. C. ; LIDDLE, J. The balanced scorecard as a performance management tool for third sector organizations: the case of the Arthur Bernardes foundation, Brazil. BAR. Brazilian Administration Review, v. 6, p. 354-366, 2009.

KAPLAN, R.; NORTON, D. A Estratégia em Ação: Balanced Scorecard. 14ª . Ed. Rio de Janeiro: Campus, 1997.

KAPLAN, R. S.; NORTON, D. P. Organização Orientada para a Estratégia: Como as empresas que adotaram o Balanced Scorecard prosperam no novo ambiente de negócios. Rio de Janeiro: Elsevier, 2000.

KAPLAN, R.; NORTON, D. Alinhamento: Utilizando o balanced scorecard para criar sinergias corporativas. Rio de Janeiro: Campus, 2006.

MARQUES, A. I. S.; BARCELOS, G. L.; TEIXEIRA, R. M. A experiência de planejamento integrado com foco em resultado do Espírito Santo. In: II Congresso CONSAD de Gestão Pública, 2009, Brasília. Revista do II Congresso Consad de Gestão Pública. Brasília: Consad, 2009. 
MELO, R. P.; PENEDO, E. S. R; MOURA, R. P. Política Versus Administração: Em Busca de um Equilíbrio Possível Através da Gestão Pública Estratégica. In: Encontro Nacional da Associação Nacional dos Programas de Pós-Graduação e Pesquisa em Administração, 33; 2009, São Paulo. Anais. Atibaia: XXXIII ENANPAD, 2009.

NIVEN, P. R. Balanced Scorecard Passo-a-Passo: Elevando o Desempenho e Mantendo Resultados. Rio de Janeiro: Ed. Qualitymark, 2007.

OLENIKE, J. E.; AMARAL, G. L.; AMARAL, L. M. F.; STEINBRUCH, F. Estudo Sobre Carga Tributária/PIB X IDH: Cálculo do IRBES (Índice de Retorno de Bem Estar à Sociedade) Ed. 2012 - Com A Utilização De Índices Recentes. Estudos do IBPT. Disponível em:<http://ibpt.com.br/img/_publicacao/14191/196.pdf?PHPSESSID=8d54f9c72afca5fa167b 43b12abe7272>. Acesso em: 21 mar. 2012.

PETERS, G. B; PIERRE, J. (Org.). Administração Pública. Coletânea. São Paulo: Editora Unesp, 2010.

RAUPP, F. M.; BEUREN, I. M. Metodologia da pesquisa aplicável às ciências sociais. In: BAUREN, Ilse Maria (Org.). Como elaborar trabalhos monográficos em contabilidade: teoria e prática. $3^{\mathrm{a}}$ ed. São Paulo: Atlas, 2006.

SILVA NETO, J. M.; MELO, R. P.; PEREIRA, S. A. Resultados Notáveis na Administração Pública: Avaliação de Programas Utilizando Mapas Estratégicos e o Balanced Scorecard In: Encontro Nacional da Associação Nacional dos Programas de PósGraduação e Pesquisa em Administração, 30; 2006, Salvador. Anais. Atibaia: XXX ENANPAD, 2006. 